\title{
Laporan kasus berbasis bukti \\ Perbandingan Efektivitas Isoniazid pada Preparat Kombinasi Isoniazid dan Rifampisin pada Anak dengan Infeksi Laten Tuberkulosis
}

\author{
Dhyniek Nurul FLA, Nastiti Kaswandhani \\ Departemen Ilmu Kesehatan Anak Fakultas Kedokteran Universitas Indonesia/RS D. Cipto Mangunkusumo, Jakarta
}

\begin{abstract}
Latar belakang. Terapi infeksi laten tuberculosis (TB) dengan INH selama 6-12 bulan telah lama digunakan sebagai rejimen standar. Waktu terapi yang lama menyebabkan angka kepatuhan terhadap pengobatan rendah sehingga dicari rejimen terapi lain yang mempunyai durasi lebih singkat.

Tujuan. Mengetahui efektivitas terapi kombinasi INH dan rifampisin selama 3 bulan dibandingkan dengan terapi INH 6 bulan pada anak dengan infeksi laten TB.

Metode. Penelusuran pustaka database elektronik yaitu Pubmed, Cochrane, dan Highwire.

Hasil. Studi uji kontrol acak prospektif selama lebih dari 11 tahun (1995-2005) terhadap 926 anak < 15 tahun yang menderita laten TB mendapatkan angka ketidakpatuhan lebih tinggi pada kelompok mendapat terapi INH 9 bulan, dibanding kelompok yang mendapat terapi INH dan rifampisin 4 bulan ( $\mathrm{p}=0,011)$. Pemberian rejimen INH dan rifampisin selama 3 bulan mampu mencegah infeksi menjadi lebih berat dan efektif bagi keadaan subklinis. Meta-analisis terhadap 5 uji klinis acak terkontrol juga menyokong hasil yang sama. Studi kohort retrospektif terhadap 335 anak $<5$ tahun, menunjukkan bahwa kemoprofilaksis kombinasi INH rifampisin yang diberikan selama 3 bulan, lebih baik $(69,6 \%)$ secara signifikan dibandingkan kepatuhan terhadap kemoprofilaksis INH saja $(27,6 \%)$ yang diberikan selama 6 bulan ( $<<0,001$; OR 4,9; IK 95\% 2,4-10,36).

Kesimpulan. Terapi infeksi laten TB dengan INH dan rifampisin selama 3 atau 4 bulan terbukti sama efektifnya dengan terapi
\end{abstract} standar INH selama 6-12 bulan. Sari Pediatri 2016;17(6):485-90.

Kata kunci: infeksi TB laten, isoniazid, rifampisin, anak

\section{Evidence base case report Efficacy of Isoniazid (INH) from Combination Preparation of Isoniazid and Rifampicin for Children with Latent Tuberculosis (TB)}

Dhyniek Nurul FLA, Nastiti Kaswandhani

Background. Six to twelve months of daily isoniazid is the standard treatment for latent M. tuberculosis infection, however it has a low compliance rates, thus limiting treatment effectiveness. Shorter treatment duration could increase the compliance, the new regimen with same effectiveness may apply in this matter.

Objective. To evaluate the effectiveness of INH combined with rifampicin for 3 months compared to INH 6 months in children suffering from latent TB.

Methods. Literature search using electronic database Pubmed, Cochrane and Highwire.

Results. Prospective, randomized, controlled study was conducted over an 11-year period $(1995-2005)$ to 926 children < 15 years with latent $\mathrm{TB}$ showed that patients who received isoniazid monotherapy were less compliant than were those who received shortcourse combination therapy $(\mathrm{P}=.011)$. Short-course regimens prevent progression of infection to disease and are as effective against subclinical disease. Meta-analysis (five RCTs perlu disebutkan kepanjangannnya) found that shorter-course of therapy with rifampin plus isoniazid was equivalent to standard therapy with isoniazid in terms of efficacy. Retrospective cohort study of 335 children with age $<5$ years showed that adherence to a 3-month chemoprophylaxis regimen of isoniazid and rifampicin (3HR) was significantly better than adherence to a 6-month chemoprophylaxis regimen of isoniazid only (69.6\% vs. 27.6\%; OR 4.97; 95\%CI 2.40-10.36). Conclusions. Shorter-course therapy with rifampin plus isoniazid was equivalent to standard therapy with isoniazid monotherapy in terms of efficacy for children with latent TB. Sari Pediatri 2016;17(6):485-90.

Keywords: latent TB infection, isoniazid, rifampicin, children

Alamat korespondensi: Dr. Nastiti Kaswandani, Sp.A(K). Departemen IKA FKUI/RS Cipto Mangunkusumo. JL, Diponegoro 71, Jakarta Pusat. Tel. +6221-3916043, 3148930. E-mail: nkaswandani@yahoo.com 
Dhyniek Nurul FLA dkk: Perbandingan efektivitas isoniazid pada preparat kombinasi isoniazid dan rifampisin

T Terapi pasien dengan TB aktif merupakan prioritas utama dalam mengontrol infeksi $\mathrm{TB}$, namun identifikasi dan terapi pasien dengan infeksi laten TB juga penting. Infeksi laten TB adalah keadaan yang ditandai dengan respon imun terhadap infeksi Mycobacterium tuberculosis sebelumnya tanpa bukti klinis adanya tuberkulosis aktif.

Terapi infeksi laten TB dengan isoniazid (INH) akan mengurangi kejadian perkembangan infeksi TB menjadi aktif dan menurunkan jumlah orang dewasa yang akan menularkan pada orang lain. Pemberian kemoprofilaksis INH dalam 3, 6, dan 12 bulan menurunkan risiko TB sebesar 21\%, 65\%, dan $75 \%$. Data terakhir menunjukkan bahwa pemberian INH selama 9 bulan dapat memberikan dampak efek perlindungan yang optimal, sehingga rejimen ini secara umum disarankan oleh American Academic of Pediatrics (AAP) untuk anak-anak dan remaja., ${ }^{1,2}$

Terapi dengan INH selama 6-12 bulan telah lama digunakan sebagai rejimen standar dalam mengatasi infeksi laten TB. Waktu terapi yang lama menyebabkan angka kepatuhan terhadap pengobatan rendah sehingga dicari rejimen terapi lain dengan durasi lebih singkat. Beberapa alternatif rejimen terapi untuk infeksi laten TB diantaranya pemberian rifampisin saja selama 4 bulan, kombinasi INH dan rifampisin selama 3 bulan, kombinasi INH dan rifapentin ialah: selama 3 bulan, serta kombinasi pirazinamid dan rifampisin selama 2 bulan. Pemberian pirazinamid dan rifampisin selama 2 bulan ternyata berhubungan dengan gangguan hati berat dan kematian. ${ }^{3,4}$ The British Thoracic Society (BTS) pada tahun 1998 merekomendasikan pemberian kombinasi INH dan rifampisin selama 3 bulan sebagai alternatif terapi infeksi laten TB, dengan waktu pemberian lebih singkat, meskipun rekomendasi tersebut berdasarkan informasi yang masih terbatas. ${ }^{5}$

Pemberian terapi INH tunggal selama 6-9 bulan secara umum direkomendasikan untuk terapi infeksi laten TB, dan telah menunjukkan hasil efektif baik pada anak-anak maupun orang dewasa. Angka kepatuhan yang menurun terhadap terapi ini telah mendorong para ahli untuk mencari rejimen dengan durasi yang lebih pendek. Kombinasi INH dan rifampisin merupakan terapi alternatif dari terapi standar dengan INH. Kombinasi ini memiliki beberapa kelebihan dibandingkan terapi INH tunggal, diantaranya ialah: durasi pemberian yang lebih singkat, tingkat kepatuhan pengobatan yang lebih tinggi, dan efek samping minimal. Kasus di atas menimbulkan pertanyaan klinis sebagai berikut:, bagaimanakah efektivitas terapi kombinasi INH dan rifampisin selama 3 bulan dibandingkan dengan terapi INH 6 bulan pada anak dengan infeksi laten TB? Apakah terapi kombinasi INH dan rifampisin dapat menggantikan terapi standar INH?

Berdasarkan berbagai variasi regimen yang digunakan, perlu kajian yang membandingkan efektivitas INH dengan kombinasi INH dan rifampisin pada anak dengan infeksi laten TB.

\section{Kasus}

Seorang anak lelaki berusia 2 tahun 4 bulan datang ke Poli Respirologi RSCM Jakarta, dikonsulkan dari Poli Bedah Anak RSCM dengan diagnosis tumor Wilms dan tersangka TB paru. Pasien didiagnosis tersangka TB paru karena pada foto toraks didapatkan gambaran limfadenopati hilus kiri. Pasien direncanakan untuk dilakukan operasi laparatomi eksplorasi oleh Departemen Bedah Anak. Riwayat pasien mengalami batuk lama atau batuk hilang timbul pada pasien disangkal, tidak menderita demam lama, riwayat kontak TB disangkal, riwayat berat badan sulit naik disangkal. Pasien tinggal di rumah bersama dengan ayah, ibu, kakek, dan nenek. Pasien sudah mendapat imunisasi BCG saat berusia 2 bulan, dan terdapat scar BCG pada lengan kanan atas.

Pada pemeriksaan fisis didapatkan tanda vital dalam batas normal, tidak ada sesak ataupun sianosis. Status gizi secara klinis dan antropometris baik. Pada pemeriksaan kepala didapatkan normosefal, tidak terdapat deformitas, tidak teraba pembesaran kelenjar getah bening (KGB) leher. Pada pemeriksaan paru suara napas vesikular, tidak ada ronki ataupun mengi. Teraba massa di abdomen kuadran kanan tengah dengan ukuran $12 \times 10 \mathrm{~cm}$, permukaan rata. Pada pemeriksaan punggung tidak ditemukan gibbus. Pada foto toraks tampak infiltrat di kedua lapang paru, hilus kiri menebal. Pemeriksaan uji tuberkulin pada volar lengan kanan bawah terdapat indurasi dengan diameter $11 \mathrm{~mm}$. Pada pemeriksaan sputum bakteri tahan asam (BTA) tiga kali didapatkan hasil negatif. Setelah diagnosis sebagai tumor Wilms dengan infeksi laten TB ditegakkan, maka terapi profilaksis TB dimulai dengan INH $1 \times 150 \mathrm{mg}$ per oral. 
Dua bulan setelah pasien diberi terapi profilaksis TB, pasien dilakukan laparatomi eksplorasi dan nefrektomi ginjal kanan. Pemeriksaan patologi anatomi (PA) dan dikonfirmai sesuai dengan nefroblastoma (tumor Wilms) stadium I favourable dan pasien mulai mendapat kemoterapi dengan vinkristin dan daktinomisin. Sedangkan terapi profilaksis TB dengan INH dilanjutkan sampai 6 bulan.

\section{Metode penelusuran}

Prosedur pencarian literatur untuk menjawab masalah tersebut, maka dilakukan penelusuran pustaka secara online dengan mempergunakan instrumen pencari Pubmed, Cochrane, dan Highwire. Kata kunci yang digunakan adalah "isoniazid", "rifampin or rifampicin", "latent tuberculosis infection" dan "children". Berdasarkan metode penelusuran dengan kriteria tersebut, didapatkan 243 artikel, namun setelah ditelaah lebih lanjut terdapat 4 artikel yang dianggap relevan dengan masalah. Levels of evidence ditentukan berdasarkan klasifikasi yang dikeluarkan oleh Oxford Centre for Evidence-Based Medicine.

\section{Hasil penelusuran literatur}

\section{Studi Kohort retrospektif (level of evidence $2 b$ )}

1. Studi terhadap 335 anak berusia $<5$ tahun yang diketahui memiliki kontak serumah dengan 243 kasus TB paru dewasa selama 4 tahun. Sebanyak sembilan puluh sembilan $(27,4 \%)$ anak didiagnosis penyakit TB, $93(25,8 \%)$ didiagnosis infeksi TB, dan 134 (37,1\%) didiagnosis terkena pajanan TB. Kepatuhan terhadap OAT $82,6 \%$, lebih baik secara signifikan dibandingkan 44,2\% kepatuhan terhadap kemoprofilaksis TB $(\mathrm{p}<0,001 ;$ Odds ratio 6,83; interval kepercayaan (IK) 95\% 3,6-12,96). Kepatuhan terhadap kemoprofilaksis kombinasi INH rifampisin yang diberikan selama 3 bulan $69,6 \%$, lebih baik secara signifikan dibandingkan $27,6 \%$ kepatuhan terhadap kemoprofilaksis INH saja yang diberikan selama 6 bulan $(\mathrm{p}<0,001$; OR 4,9; IK 95\% 2,4-10,36). Pada penelitian ini dapat menyimpulkan bahwa pemberian kemoprofilaksis kombinasi INH dan rifampisin selama 3 bulan dapat dipertimbangkan untuk meningkatkan kepatuhan terhadap kemoprofilaksis TB. ${ }^{6}$
2. Penelitian terhadap 334 pasien anak 0-15 tahun dengan infeksi laten TB mendapat terapi kombinasi INH dan rifampisin selama 3 bulan. Dari 252 pasien yang dapat dipantau, 3 (1,19\%) pasien berkembang menjadi sakit TB yaitu pada pemantauan 6 bulan, 6 tahun 11 bulan, dan 7 tahun 10 bulan setelah mulai terapi profilaksis. Semua anak memiliki tingkat kepatuhan yang baik selama 3 bulan pemberian terapi. Tidak ada pasien yang mengalami efek samping ikterus selama pemberian terapi profilaksis. Pada sedikit kasus dibutuhkan antiemetik untuk mual atau muntah, dengan fungsi hati yang normal. Tiga kasus yang berkembang menjadi aktif terjadi selama pemantauan, dengan rata-rata lama pemantauan 12,35 tahun, sehingga tingkat TB klinis adalah 0,964/1000 orang per tahun (IK 95\% 0,0199 2,816). Sebagai kesimpulan dari penelitian ini, pemantauan terhadap kasus yang diterapi dengan kombinasi INH dan rifampisin, dengan rata-rata lama pemantauan 12,35 tahun, menunjukkan angka TB aktif dibawah 1/1000 tahun pasien. $\mathrm{Hal}$ ini menunjukkan bahwa kombinasi INH dan rifampisin memiliki efikasi yang sangat tinggi dalam terapi infeksi laten TB pada anak. ${ }^{7}$

Uji Kontrol Acak Prospektif (level of evidence 1b)

1. Studi uji kontrol acak prospektif selama lebih dari 11 tahun (1995-2005) terhadap 926 anak $<15$ tahun yang memenuhi kriteria infeksi laten TB berdasarkan the International Union Againts Tuberculosis and Lung Disease, AAP, dan BTS. Kelompok A $(\mathrm{n}=232)$ mendapat terapi INH 9 bulan, kelompok B $(n=238)$ mendapat terapi INH dan rifampisin 4 bulan, kelompok C $(n=232)$ mendapat terapi INH dan rifampisin 4 bulan dan kelompok D ( $\mathrm{n}=220)$ mendapat terapi INH dan rifampisin 3 bulan. Secara keseluruhan, total 850 dari $926(91,8 \%)$ pasien memiliki kepatuhan yang baik. Angka ketidakpatuhan lebih tinggi pada kelompok A dibanding kelompok B ( $\mathrm{p}=0,011)$, sementara pada kelompok $\mathrm{C}$ dan $\mathrm{D}$ tidak didapatkan perbedaan yang bermakna $(\mathrm{p}=0,533)$. Pasien dengan tingkat kepatuhan tinggi atau sedang, pada pemeriksaan radiologis mendeteksi adanya penyakit aktif seperti adenopati hilus dan atau lesi parenkim paru setelah 4 bulan terapi, mendapatkan 48 dari 200 (24\%) pasien di kelompok A, sementara 26 dari 220 
Dhyniek Nurul FLA dkk: Perbandingan efektivitas isoniazid pada preparat kombinasi isoniazid dan rifampisin

$(11,8 \%)$ pasien pada kelompok B ( $\mathrm{p}=0,001)$. Temuan radiologis baru ditemukan pada 30 dari $221(13,6 \%)$ dari kelompok C, dan 23 dari 209 (11\%) pasien dari kelompok D ( $\mathrm{p}=0,418)$. Dapat disimpulkan bahwa pemberian rejimen INH dan rifampisin selama 3 bulan memiliki efikasi yang setara dengan pemberian INH dan rifampisin selama 4 bulan, dan kedua rejimen ini lebih superior dibandingkan pemberian INH selama 9 bulan. Angka kepatuhan lebih tinggi dengan pemberian rejimen yang lebih singkat, lebih efektif dalam mengatasi infeksi mikobakterium yang resisten INH dan sensitif rifampisin. ${ }^{8}$

\section{Studi meta-analisis ( level of evidence 1a)}

Studi dilakukan terhadap 5 uji klinis acak terkontrol pada 1926 orang dewasa, membandingkan pemberian rejimen INH dan rifampisin selama 3 bulan dengan 6-12 bulan terapi standar dengan INH. Tiga penelitian dilakukan pada subyek dengan infeksi HIV $(n=1390)$, sementara 2 penelitian lain dilakukan pada bukan HIV atau status HIV tidak diketahui $(\mathrm{n}=536)$. Dua penelitian menggunakan rejimen terapi standar INH dengan durasi $>6$ bulan, sementara 3 penelitian menggunakan rejimen INH selama 6 bulan. Kepatuhan terhadap terapi dilaporkan pada 4 dari 5 penelitian, dan lebih tinggi pada pasien yang mendapatkan terapi kombinasi INH dan rifampisin dalam jangka waktu yang lebih pendek dibanding pasien terapi standar dengan INH. Analisis dilakukan pada 972 pasien yang diterapi kombinasi INH dan rifampisin dan 954 pasien diterapi dengan INH. Durasi pemantauan bervariasi dari 13 - 36,5 bulan. Dijumpai 41 (4,2\%) pasien yang mendapat terapi INH dengan rifampisin berkembang menjadi penyakit TB, sementara yang mendapat terapi INH sebanyak 39 (4,1\%) pasien. Secara keseluruhan frekuensi TB setara pada tiap rejimen. Sebanyak empat puluh delapan $(4,9 \%)$ pasien yang mendapat terapi INH dengan rifampisin menghentikan pengobatan karena efek samping yang berat, sementara yang mendapat terapi INH $46(4,8 \%)$ pasien. Insidens TB dijumpai pada $41(4,2 \%)$ pasien yang mendapat kemoprofilaksis INH dan rifampisin menjadi TB aktif, dibandingkan dengan pasien $(4,1 \%) 39$ yang mendapat INH saja $(0 \%, p=0,83)$. Sebagai kesimpulan meta-analisis ini menunjukkan bahwa pemberian rejimen INH dan rifampisin selama 3 bulan maupun terapi standar dengan INH selama 6-12 bulan memiliki kesetaraan dalam efektivitas dan keamanan.?

\section{Pembahasan}

Infeksi laten TB adalah infeksi Mycobacterium tuberculosis, yang hidup dalam sel namun tidak menyebabkan penyakit aktif. Sekali terinfeksi, kesempatan untuk berkembang menjadi penyakit aktif. Pada individu yang imunokompeten paling tinggi 2 tahun pertama setelah paparan, dengan setengah kasus terjadi dalam waktu 5 tahun, dari keseluruhan 5\%-10\% kasus. ${ }^{10}$ Sekitar 50\%-60\% anak yang tinggal dengan pasien TB baru dewasa dengan BTA sputum positif akan terinfeksi TB. Kira-kira 10\% dari jumlah tersebut akan mengalami sakit TB. Infeksi TB pada anak kecil memiliki risiko yang besar untuk berkembang menjadi TB berat (misalnya TB meningitis atau TB milier) sehingga diperlukan kemoprofilaksis untuk mencegah terjadinya sakit TB. Tata laksana terhadap infeksi laten TB merupakan strategi paling efektif dalam mencegah perkembangan penyakit di kemudian hari. Terapi profilaksis ini ditujukan terhadap pasien dengan kecurigaan terkena infeksi (ditandai dengan hasil positif pada uji tuberkulin) dan pada pasien yang memiliki risiko tinggi untuk perkembangan menjadi penyakit aktif. ${ }^{11}$

Rejimen terapi infeksi laten TB telah dievaluasi dan digunakan selama lebih dari 6 dekade. Akhirakhir ini perhatian terhadap kepatuhan pengobatan, ${ }^{12}$ biaya, ${ }^{13}$ dan peningkatan angka resistensi obat, ${ }^{14}$, telah mendorong peneliti untuk mencari rejimen terapi infeksi laten TB yang dapat diberikan dalam waktu lebih singkat. Sayangnya hanya sedikit sekali penelitian yang dilakukan terhadap anak. Keuntungan terapi kombinasi, diantaranya durasi pengobatan yang lebih singkat dan cakupan yang lebih luas. ${ }^{15}$

Rejimen terapi infeksi TB laten diantaranya pemberian INH selama 6 atau 9 bulan, rifampisin selama 4 bulan, kombinasi INH dan rifampisin selama 3 bulan, kombinasi INH dan rifapentin selama 3 bulan, serta kombinasi pirazinamid dan rifampisin selama 2 bulan. ${ }^{15}$ Meskipun AAP dan Centers for Disease Control and Prevention (CDC) telah lama merekomendasikan INH sebagai terapi infeksi laten TB pada anak. Namun dijumpai efektivitas INH 6 bulan pada praktik klinis lebih rendah $(<50 \%)$ daripada efikasi yang ditunjukkan pada uji klinis karena kepatuhan untuk menyelesaikan terapi INH sampai 9 bulan Pemberian rejimen dengan durasi yang lebih singkat baik dalam bentuk rejimen tunggal maupun kombinasi memperlihatkan angka kepatuhan yang lebih tinggi. ${ }^{15}$ 
Pemilihan rejimen terapi harus seimbang antara efikasi (derajat proteksi yang diperlihatkan pada uji klinis) dan efek samping (relatif rendah pada anak pada semua jenis rejimen), kepatuhan, dan sensitivitas obat terhadap isolat (didapat dari penderita TB yang mengalami kontak dengan anak). Rejimen yang memiliki efikasi tinggi hasil terapi, akan terbatas apabila pasien tidak menyelesaikan terapi secara sempurna. Untuk anak berusia 12 tahun atau lebih, alternatif terbaik untuk menggantikan terapi infeksi TB laten dengan INH selama 9 bulan adalah regimen INH dan ripafentin 12 minggu yang diberikan dengan pengawasan. Rejimen diberikan dengan dosis terkecil dalam waktu yang singkat, efektif, dapat ditoleransi dengan baik, dan merupakan rejimen. Sayangnya, rejimen ini tidak dianjurkan untuk diberikan tanpa pengawasan dan sampai saat ini masih belum tersedia di Indonesia. Keterbatasan ketersediaan rifapentin menyebabkan penggunaan rejimen ini masih belum meluas.

Alternatif lain dari terapi INH selama 9 bulan adalah pemberian rifampisin selama 4 bulan untuk meningkatkan kepatuhan, namun belum ada penelitian yang menilai efektivitas terapi ini pada anak. The British Thoracic Society (BTS) merekomendasikan pemberian kombinasi INH dan rifampisin selama 3 bulan sebagai alternatif terapi infeksi laten TB. Penelitian yang dilakukan Spyridis dkk menyimpulkan bahwa pemberian rejimen INH dan rifampisin selama 3 bulan memiliki efikasi yang setara dengan pemberian INH dan rifampisin selama 4 bulan, dan kedua rejimen ini lebih superior dibandingkan pemberian INH selama 9 bulan. ${ }^{8}$ Hal yang serupa didapatkan dari studi meta-analisis yang dilakukan oleh Ena dan Valls yang menyimpulkan bahwa pemberian rejimen INH dan rifampisin selama 3 bulan dan terapi standar dengan INH selama 6-12 bulan memiliki kesetaraan dalam efikasi, proporsi efek samping berat yang terjadi, dan kematian. ${ }^{9}$

\section{Kesimpulan}

Berdasarkan penelitian ilmiah yang telah dipaparkan sebelumnya dapat disimpulkan bahwa terapi profilaksis infeksi laten TB dengan INH dan rifampisin selama 3 atau 4 bulan terbukti sama efektifnya dengan terapi standar dengan INH selama 6-12 bulan. Terapi kombinasi ini memiliki keuntungan tingkat kepatuhan yang lebih tinggi daripada monoterapi.

\section{Daftar pustaka}

2. Pediatric Tuberculosis Collaborative Group. Targeted tuberculin skin testing and treatment of latent tuberculosis infection in children and adolescents. Pediatrics 2004;114:1175-201.

3. Comstock GW. How much isoniazid is needed for prevention of tuberculosis among immunocompetent adults? Int J Tuberc Lung Dis 1999;3:847-50.

4. CDC. Fatal and severe hepatitis associated with rifampin and pyrazinamide for the treatment of latent tuberculosis infection-New York and Georgia, 2000. MMWR 2001; 50:289-91.

5. CDC. Update: fatal and severe liver injuries associated with rifampin and pyrazinamide for latent tuberculosis infection, and revisions in American Thoracic Society/ CDC recommendations_- United States, 2001. MMWR 2001;50:733-5.

6. Control and prevention of tuberculosis in the United Kingdom: code of practice 2000. Joint Tuberculosis Committee of the British Thoracic Society. Thorax 2000;55:887-901

7. van Zyl S, Marais BJ, Hesseling AC, Gie RP, Beyers N, Schaaf HS. Adherence to anti-tuberculosis chemoprophylaxis and treatment in children. Int J Tuberc Lung Dis 2006;10:13-8.

8. Bright-Thomas R, Nandwani S, Smith J, Morris JA, Ormerod LP. Effectiveness of 3 months of rifampicin and isoniazid chemoprophylaxis for the treatment of latent tuberculosis infection in children. Arch Dis Child 2010;95:600-2.

9. Spyridis NP, Spyridis PG, Gelesme A, Sypsa V, Valianatou M, Metsou F, dkk. The effectiveness of a 9-month regimen of isoniazid alone versus 3-and 4-month regimens of isoniazid plus rifampin for treatment of latent tuberculosis infection in children: results of an 11-year randomized study. Clin Infect Dis 2007;45:715-22.

10. Ena J, Valls V. Short-course therapy with rifampin plus isoniazid, compared with standard therapy with isoniazid, for latent tuberculosis infection: a metaanalysis. Clin Infect Dis 2005;40:670-6.

11. Enarson DA. The epidemiological basis of tuberculosis control. Dalam: Davies PDO, Barnes PF, Gordon SB, penyunting. Clinical tuberculosis. Edisi ke-2. London: Chapman \& Hall;1998.h.711-823.

12. American Thoracic Society. Targeted tuberculin testing and treatment of latent tuberculosis infection. Am J Respir Crit Care Med 2000;161:S221-47. 
13. Horsburgh CR, Jr., Goldberg S, Bethel J, Chen S, Colson PW, Hirsch-Moverman Y, dkk. Latent TB infection treatment acceptance and completion in the United States and Canada. Chest 2010;137:401-9.

14. Finnell SM, Christenson JC, Downs SM. Latent tuberculosis infection in children: a call for revised treatment guidelines. Pediatrics 2009;123:816-22.
15. Smith SE, Kurbatova EV, Cavanaugh JS, Cegielski JP. Global isoniazid resistance patterns in rifampin-resistant and rifampin-susceptible tuberculosis. Int J Tuberc Lung Dis 2012;16:203-5.

16. Cruz AT, Ahmed A, Mandalakas AM, Starke JR. Treatment of latent tuberculosis infection in children. Pediatr Infect Dis J 2013;30:1-11. 